\title{
PENINGKATAN PENGETAHUAN TENTANG HIPERTENSI DENGAN METODE PENDIDIKAN KESEHATAN DI LINGKUNGAN MASYARAKAT
}

\author{
Dwi Retnaningsih ${ }^{1}$, Novi Larasati ${ }^{2}$ \\ ${ }^{1,2}$ ) Program Studi Keperawatan, Fakultas Keperawatan, Bisnis, dan Teknologi, \\ Universitas Widya Husada Semarang \\ e-mail: dwiretnaningsih81@yahoo.co.id
}

\begin{abstract}
Abstrak
Hipertensi merupakan masalah besar di Indonesia dengan prevalensi sebesar 25,8\%. Data di Provinsi Jawa Tengah tahun 2015 urutan pertama sebesar 57,87\%. Peningkatan kasus hipertensi disebabkan oleh faktor kurangnya pengetahuan, sikap yang dimiliki masyarakat mengenai hipertensi sehingga masyarakat memiliki perilaku yang rendah dalam melakukan pencegahan hipertensi. Tingkat pendidikan yang rendah dapat mempengaruhi terjadinya hipertensi yang disebabkan oleh gaya hidup, perilaku, dan lingkungan. Tujuan dilakukan pendidikan kesehatan untuk meningkatkan pengetahuan pada kelompok masyarakat dengan hipertensi. dengan menggunakan metode pendidikan kesehatan. Metode implementasi pendidikan kesehatan terdiri dari tahap persiapan, perijinan dan pelaksanaan. Pada tahap persiapan, dilakukan survei di lingkungan masyarakat sekitar dan penyusunan media pembelajaran. dengan melakukan kunjungan pada masyarakat yang menderita hipertensi di wilayah Mijen Semarang dengan pendidikan kesehatan serta memberikan asuhan keperawatan. Pendidikan kesehatan dilakukan secara langsung dengan menggunakan lembar balik. Hasil yang diperoleh adalah kegiatan pendidikan kesehatan berjalan dengan baik dan lancar, masyarakat aktif dan mengikuti seluruh kegiatan dengan baik.
\end{abstract}

Kata kunci: Pendidikan Kesehatan, Hipertensi, Pengetahuan

\begin{abstract}
Hypertension is a big problem in Indonesia with a prevalence of $25.8 \%$. Data in Central Java Province in 2015 ranked first at $57.87 \%$. The increase in hypertension cases is caused by a lack of knowledge, attitudes that people have about hypertension so that people have low behavior in preventing hypertension. Low levels of education can affect the occurrence of hypertension caused by lifestyle, behavior, and environment. The purpose of health education is to increase knowledge in groups of people with hypertension. using health education methods. The method of implementing health education consists of the stages of preparation, licensing and implementation. In the preparation stage, a survey was conducted in the surrounding community and the preparation of learning media. by visiting people who suffer from hypertension in the Mijen area of Semarang with health education and providing nursing care. Health education is carried out directly using flipcharts. The results obtained are health education activities run well and smoothly, the community is active and participates in all activities well.
\end{abstract}

Keywords: Health Education, Hypertension, Knowledge

\section{PENDAHULUAN}

Hipertensi adalah peningkatan tekanan darah sistolik lebih dari $140 \mathrm{mmHg}$ dan tekanan darah diastolik lebih dari $90 \mathrm{mmHg}$ pada dua kali pengukuran dengan selang waktu lima menit dalam keadaan cukup istirahat/ tenang. Peningkatan tekanan darah dengan jangka waktu yang lama dapat menimbulkan kerusakan pada ginjal, jantung, dan otak apabila tidak dilakukan pengobatan secara dini (Kementrian Kesehatan Republik, 2017). Prevalansi hipertensi nasional berdasarkan Riskesdas 2013 sebesar $25,8 \%$ dengan orang yang mengalami hipertensi hanya $1 / 3$ yang terdiagnosis sedangkan $2 / 3$ tidak terdiagnosis dan $0,7 \%$ orang yang terdiagnosis tekanan darah tinggi dengan memiliki kebiasaan meminum obat hipertensi. Hal ini menunjukkan bahwa sebagian besar penderita hipertensi tidak menyadari menderita hipertensi (Kementrian Kesehatan Republik, 2017).

Faktor resiko hipertensi adalah umur, jenis kelamin, riwayat keluarga, genetik, kebiasaan merokok, konsumsi garam, konsumsi lemak jenuh, kebiasaan minum-minuman beralkohol, obesitas, 
kurang aktivitas fisik, stress dan penggunaan estrogen (Kementrian Kesehatan Republik, 2017). Munculnya masalah kesehatan tidak hanya disebabkan oleh kelalian individu, namun dapat pula disebabkan oleh ketidaktahuan masyarakat sebagai akibat dari kurangnya informasi yang benar mengenai suatu penyakit (Rahmadiana, 2012). Rendahnya pengetahuan tenaga kesehatan, pasien, dan masyarakat tentang hipertensi merupakan penyebab utama tidak terkontrolnya tekanan darah, terutama pada pasien hipertensi di Asia (Park J.B., Kario, K., dan Wang, 2015).

Pengetahuan pasien hipertensi yang sudah baik itu diperoleh dari media elektronik seperti televisi, radio, internet, membaca majalah atau lewat promosi kesehatan dari petugas kesehatan dan juga dari teman-teman terdekat yang mengetahui tentang penyakit hipertensi (Dirhan, 2012). Adanya peningkatan pengetahuan tentang hipetensi setelh pemberian pendidikan dengan skor rerata yaitu 4,46 (sebelum) dan 13,97 (setelah), yang artinya pemberian pendidikan kesehatan dapat meningkatkan pengetahuan mengenai hipertensi pada lansia (Fitria, W. D. And Candrasari, 2010).

Pengetahuan bisa didapatkan melalui pendidikan kesehatan. Pendidikan kesehatan tentang perawatan hipertensi pada anggota keluarga dapat memberikan informasi yang dibutuhkan keluarga yang dapat meningkatkan pengetahuan keluarga sehingga keluarga dapat menentukan sikap yang lebih baik dalam perawatan hipertensi anggota keluarga (Mardhiah, A., Abdullah, 2013). Penyukuhan kesehatan berpengaruh terhadap peningkatan pengetahuan perilaku klien hipertensi, akan meningkatkan pola hidup sehingga dapat mengontrol tekanan darah dengan baik (Purwati, R. D., Bidjuni, H. And Babakal, 2014). Berdasarkan hal tersebut maka sangat diperlukan adanya kegiatan pemberian pendidikan kesehatan mengenai hipertensi di lingkungan masyarakat. Tujuannya untuk mengetahui gambaran tingkat pengetahuan di lingkungan masyarakat sekitar tentang hipertensi, yang dilakukan dengan menggunakan metode pendidikan kesehatan

\section{METODE}

Kegiatan ini terdiri dari tahap persiapan, perijinan dan pelaksanaan. Pada tahap persiapan, dilakukan survei di lingkungan masyarakat sekitar dan penyusunan media pembelajaran. Pada tahap perijinan, dilakukan dengan meminta ijin di lingkungan dan kelurahan setempat untuk kesediaan diberikannya ijin melakukan pendidikan kesehatan. Sedangkan pada tahap pelaksanaan, metode implementasi dilakukannya pemberian materi pembelajaran berupa lembar balik pada lingkungan masyarakat.

Subjek dalam kegiatan penyuluhan ini adalah masyarakat dengan hipertensi di wilayah Mijen Semarang. Pada tahap awal, dilakukan pengukuran tingkat pengetahuan yang berkaitan dengan hipertensi. Adapun media yang digunakan adalah lembar balik dengan tampilan yang menarik dan mudah dipahami. Pengetahuan dasar dalam lembar balik tersebut meliputi pengertian hipertensi, penyebab hipertensi, tanda \& geaja hipertensi, komplikasi, dan cara penanganan hipertensi melalui perbaikan pola hidup.

\section{HASIL DAN PEMBAHASAN}

Hasil pengukuran tingkat pengetahuan pada klien menunjukkan masih rendahnya tingkat pengetahuan tentang hipertensi. Hal itu dapat dilihat saat dilakukannya identifikasi tingkat pengetahuan klien belum memahami tetang hipertensi. Pada saat dilakukan pengkajian terdapat hasil, Klien mengatakan nyeri kepala hingga tengkuk belakang dengan Tekanan Darah 150/110 mmHg. Setelah dilakukan identifikasi tingkat pengetahuan, klien diberikan edukasi mengenai pengetahuan tentang hipertensi berupa media lembar balik. Bahasa yang digunakan dalam media lembar balik disesuaikan dengan kondisi klien dalam penyampaian materi lebih dipilih istilah-istilah umum yang mudah dipahami dan tidak banyak menggunakan istilah medis. Penyesuaian bahasa merupakan hal penting karena dengan bahasa yang mudah dipahami dan dengan pemisalan-pemisalan yang sederhana, materi dapat diterima dan dipahami lebih mudah. Berikut salah satu dokumentasi kegiatan; 

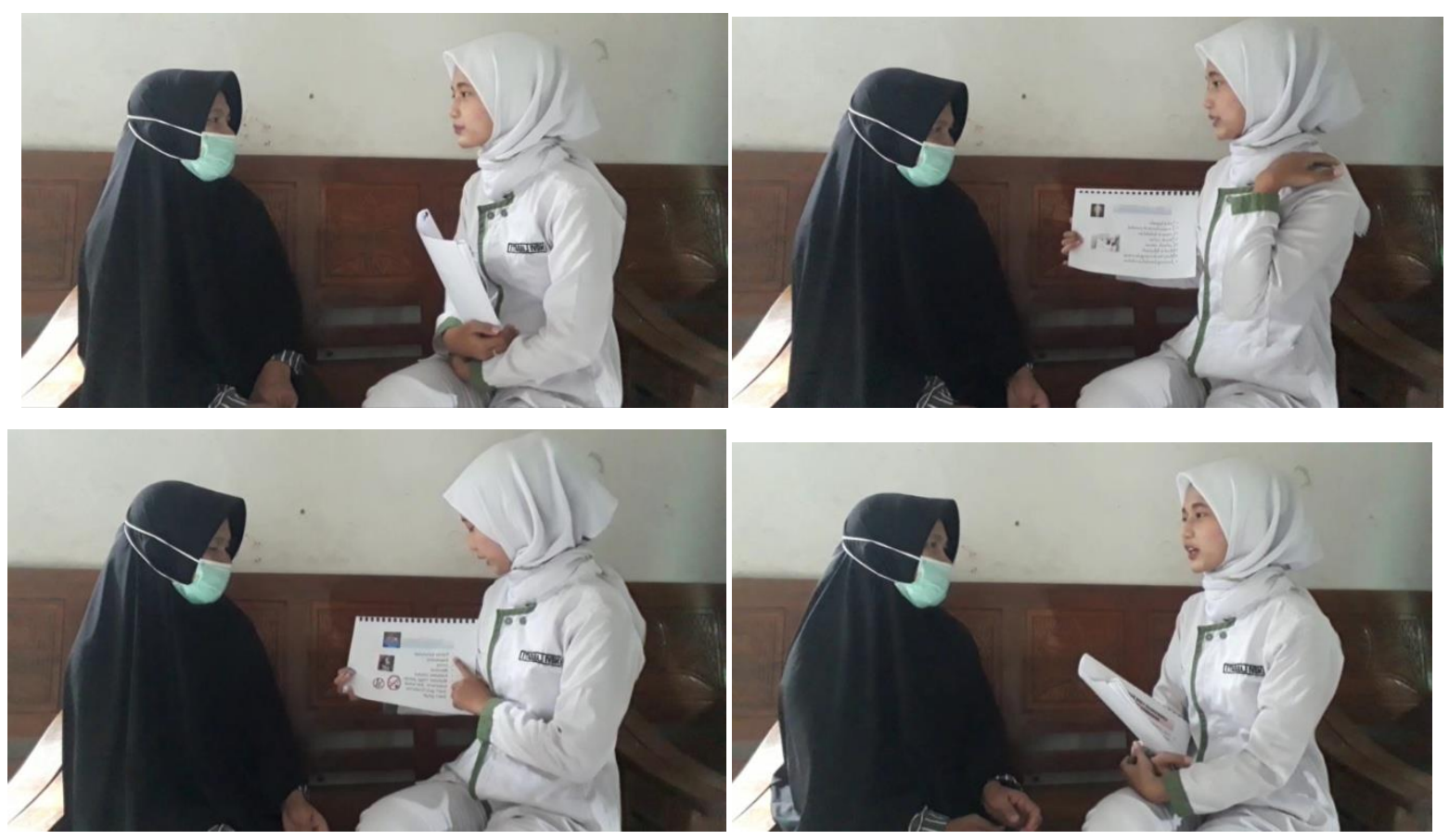

Gambar: Pelaksanaan pendidikan kesehatan mengenai hipertensi

Hipertensi sebagian besar terjadi pada usia 31 - 55 tahun dan umumnya berisiko lebih tinggi pada generasi di atas 40 tahun. Bahkan bisa lebih tinggi pada usia lebih dari 60 tahun. Secara fisiologis, hubungan antara usia dan peningkatan tekanan darah terjadi karena adanya perubahan elastisitas dinding pembuluh darah dari waktu ke waktu, proliferasi kolagen, dan endapan kalsium yang berhubungan dengan aterosklerosis (Kusumawaty, J., Hidayat, N., 2016).

Faktor risiko peningkatan tekanan darah meliputi usia, keturunan, kebiasaan merokok, konsumsi garam berlebihan, kolesterol, stres, dan kelebihan berat badan atau obesitas. Penderita hipertensi biasanya tidak memiliki gejala khusus hingga gejala ringan seperti pusing, cemas, mimisan, dan sakit kepala. Peningkatan tekanan darah hanya akan terlihat setelah pemeriksaan kesehatan (Sutanto, 2010).

Tingkat pendidikan yang rendah dapat mempengaruhi terjadinya hipertensi yang disebabkan oleh gaya hidup, perilaku, lingkungan, dan sistem. Tingkat pendidikan sangat erat kaitannya dengan gaya hidup. Masyarakat berpengetahuan rendah cenderung memiliki kesadaran untuk berperilaku gaya hidup yang kurang sehat seperti perilaku merokok. (Retnaningsih et al., 2017) Selain itu, aspek psikologis mengenai beban kerja dan lingkungan kerja dapat menjadi pemicu timbulnya gangguan kesehatan seseorang khususnya terkait dengan penyakit seperti hipertensi (Sinuraya, R. K., Siagian, B. J., Taufik, A., Destiani, D. P., Puspitasari, I. M., Lestari, K., \& Diantini, 2017), dijelaskan dalam penelitian bahwa ada pengaruh pendidikan kesehatan terhadap peningkatan pengetahuan keluarga dengan hipertensi. Hal ini sejalan dengan penelitian sebelumnya (Purwati, R. D., Bidjuni, H. And Babakal, 2014) terdapat pengaruh penyuluhan kesehatan terhadap peningkatan pengetahuan klien hipertensi dan penelitian Beigi dijelaskan bahwa program pendidikan efektif dalam meningkatkan pengetahun, meningkatkan manajemen diri, dan mengendalikan kebiasaan gaya hidup yang merugikan pasien dengan hipertensi (Beigi, M.A., Zibaeenezad M.J., Aghasadeghi K., Aghasadeghi, K., Jokar, A., Shekarforoush, S., \& Khazraei, 2014). Hasil penelitian bahwa program pendidikan hipertensi dapat berguna dalam meningkatkan pengetahuan tentang hipertensi (Roca, B., Nadal, E., Rovira, R.E., Valls, S., Lapuebla, C., \& Lloria, 2003).

Informasi dapat membantu mempercepat seseoarang untuk memperoleh pengetahuan. Berbagai macam informasi yang didapat oleh masyarakat terutama masalah penyakit hipertensi akan dapat meningkatkan pengetahuan masyarakat. Salah satu informasi yang didapatkan adalah penyuluhan atau pendidikan kesehatan yang diberikan oleh peneliti sehingga pengetahuan klien menjadi baik semua. Promosi kesehatan yang dilakukan dengan metode pendidikan kesehatan tentang hipertensi dan faktor risiko akibat dari hipertensi. Semakin meningkatnya pengetahuan pasien tentang hipertensi akan mendorong seseorang untuk berperilaku yang lebih baik dalam mengontrol hipertensi sehingga tekanan darahnya tetap terkendali, pengetahuan pasien mengenai hipertensi juga berpengaruh pada 
kepatuhan pasien dalam melakukan pengobatan. Seiring dengan meningkatnya pengetahuan tentang hipertensi maka dapat melakukan penatalaksanaan penyakitnya sehingga pasien menjadi lebih baik (Wulansari, J ., Ichsan, B. and Usdiana, 2013). Pengetahuan yang baik tentang hipertensi dapat mempengaruhi perilaku masyarakat dalam mencegah hipertensi. (Dwi Retnaningsih, 2019; Limbong, V ., Rumayar, A. And Kandou, 2016)Pekerjaan dapat mempengaruhi hipertensi karena dalam melakukan kerja banyak beban yang dirasakan kemudian menyebabkan seseorang seringkali stress dan cemas dalam memikirkan kondisi sakitnya. (Kurniawan, A., Armiyati, Y., \& Astuti, 2013).

Pendidikan kesehatan memberikan wawasan baru, mengurangi ketegangan dan ketakutan pada seseorang yang khawatir akan penyakitnya sehingga dapat menurunkan tekanan darah yang tadinya tinggi karena perasaan cemas dan khawatir terkait dengan penyakit yang dideritanya kemudian memicu hipertensi. Pendidikan adalah upaya persuasi atau pembelajaran kepada masyarakat, agar masyarakat mau melakukan tindakan-tindakan (praktik) untuk memelihara (mengatasi masalahmasalah), dan meningkatkan kesehatannya. Perubahan atau tindakan pemeliharaan dan peningkatan kesehatan yang dihasilkan oleh pendidikan kesehatan ini didasarkan kepada pengetahuan dan kesadarannya melalui proses pembelajaran, sehingga perilaku tersebut diharapkan akan berlangsung lama dan menetap, karena didasari oleh kesadaran (Notoatmodjo, 2010). Menurut Susanti, ada pengaruh yang signifikan antara pemberian pendidikan tentang hipertensi terhadap peningkatan pengetahuan mengelola hipertensi (Susanti, M.T , Suryani, M, 2012), sejalan dengan penelitian Bayo bahwa ada pengaruh pendidikan kesehatan terhadap pengetahuan klien tentang cara pencegahan hipertensi (Bayo, 2008).

Proses belajar dalam pendidikan kesehatan merupakan proses terjadinya perubahan kemampuan pada subjek belajar dengan keluaran yang diharapkan adalah kemampuan sebagai hasil perubahan perilaku dari sasaran didik (Notoatmodjo, 2010). Peningkatan pengetahuan yang terjadi setelah diberikan pendidikan kesehatan merupakan salah satu aspek kemampuan yang dicapai oleh sasaran didik sebagai akibat adanya proses belajar.

Pendidikan kesehatan merupakan aktifitas pembelajaran yang dirancang oleh perawat sesuai kebutuhan klien. Pencapaian tujuan pendidikan kesehatan akan lebih mudah dengan penggunaan media pembelajaran yang sesuai dan dapat meningkatkan kemudahan penerimaan informasi dan penggunaan alat bantu berupa tulisan akan lebih menghasilkan peningkatan pengetahuan daripada kata-kata (Nies, M.A., \& McEwen, 2001).

Pendidikan kesehatan sangatlah penting bagi responden terutama yang menderita hipertensi agar lebih memahami tentang bahaya dari dampak penyakit tersebut dan dapat merubah pola hidup sehat. Pendidikan kesehatan tentang gaya hidup sehat merupakan upaya untuk memberikan dorongan agar responden mampu menerapkan diet rendah garam, melakukan berolahraga secara teratur dengan melakukan jalan pagi atau menggunakan sepeda dan melakukan ktivitas dirumah, mengurangi stress dengan melakukan tidur tepat waktu dan menghindari perselisihan pemikiran dengan orang lain, mencegah kegemukan dengan mengurangi pola makan dan berhenti merokok. Hasil penelitian ini sejalan dengan penelitian Tirtana dan membuktikan terdapat pengaruh pendidikan kesehatan hipertensi terhadap perubahan pengetahuan responden tentang perilaku hidup sehat seperti mengatur pola makan dengan membatasi asupan garam, lemak, alkohol, berhenti merokok, dan mengontrol berat badan, melakukan aktivitas fisik, istirahat dan tidur (Tirtana, 2014).

\section{SIMPULAN}

Kegiatan penyuluhan dengan metode pendidikan kesehatan di lingkungan masyarakat dapat berjalan dengan baik dan lancar. Responden aktif, antusias, dan dapat bekerja sama dengan baik dan responden dapat meningkatkan dan memiliki pengetahuan serta memahami dengan baik mengenai hipertensi.

\section{SARAN}

Meningkatkan kesadaran masyarakat agar dapat melaksanakan kebiasaan hidup sehat dengan berolahraga dan memanfaatkan fasilitas pelayanan kesehatan posyandu dan tanaman obat keluarga sebagai terapi komplementer.

\section{UCAPAN TERIMAKASIH}

Ucapan terimakasih ditujukan kepada masyarakat, kader kesehatan serta lurah Mijen Semarang. 


\section{DAFTAR PUSTAKA}

Bayo, M. . (2008). Pengaruh pendidikan kesehatan terhadap pengetahuan klien tentang cara pencegahan hipertensi di kelurahan tinjomoyo Semarang.

Beigi, M.A., Zibaeenezad M.J., Aghasadeghi K., Aghasadeghi, K., Jokar, A., Shekarforoush, S., \& Khazraei, H. J. (2014). The effect of educational program on hypertension management. International Cardiovascular Research Journal, 8(3), 94-98.

Dirhan. (2012). Hubungan Pengetahuan, Sikap Dan Ketaatan Berobat Dengan Derajat Sistole Dan Diastole Pasien Hipertensi. Jurnal Ilmiah Farmasi, 9(1).

Dwi Retnaningsih. (2019). PENGABDIAN KEPADA MASYARAKAT DALAM RANGKA PEMBERDAYAAN LANSIA MENURUNKAN HIPERTENSI. Jurnal Implementasi Pengabdian Masyarakat Kesehatan, 1(2), 39-42. file:///C:/Users/Dwi Retnaningsih/Downloads/14-57-1PB.pdf

Fitria, W. D. And Candrasari, A. (2010). Peningkatan Pengetahuan Tentang Hipertensi pada Lansia di Posyandu Lansia Dukuh Gantungan Desa Makamhaji Kartasura Sukoharjo. Warta, 13, 28-36.

Kementrian Kesehatan Republik. (2017). Hipertensi. Pusat Data dan Informasi Kementerian Kesehatan Republik Indonesia.

Kurniawan, A., Armiyati, Y., \& Astuti, R. (2013). Pengaruh Pendidikan Kesehatan Pre Operasi Terhadap Tingkat Kecemasan Pada Pasien Pre Operasi Hernia di RSUD Kudus. 6(2).

Kusumawaty, J., Hidayat, N., \& G. (2016). No TitleKusumawaty, J., Hidayat, N., \& Ginanjar, E. (2016). Relationship between Gender and Hypertension Intensity of the Elderly in the Work Area of the Lakbok Health Center in Ciamis Regency. Mutiara Medika, 16 (2), 46-51. Mutiara Medika, $16(2), 46-51$.

Limbong, V ., Rumayar, A. And Kandou, G. (2016). Hubungan Pengetahuan dan Sikap Dengan Kejadian Hipertensi di Wilayah Kerja Puskesmas Tateli Kabupaten Minahasa. Jurnal KESMAS, 7(4).

Mardhiah, A., Abdullah, A. A. H. (2013). Pendidikan Kesehatan Dalam Peningkatan Pengetahuan, Sikap Dan Keterampilan Keluarga Dengan Hipertensi Pilot Study. Jurnal Ilmu Keperawatan, 111121.

Nies, M.A., \& McEwen, M. (2001). Community health nursing: Promoting the health of population (3rd ed.). W.B. Saunders Company.

Notoatmodjo. (2010). Metodologi Penelitian Kesehatan. PT. Rineka Cipta.

Park J.B., Kario, K., dan Wang, J. . (2015). "Systolic Hypertension; $n$ Increasing Clinical Challange in Asia" dalam Hypertension Research. 38(4), 227-236.

Purwati, R. D., Bidjuni, H. And Babakal, A. (2014). Pengaruh Penyuluhan Kesehatan Terhadap Pengetahuan Perilaku Klien Hipertensi di Puskesmas Bahu Manado. Journal Keperawatan, 2(2), $1-8$.

Rahmadiana, M. (2012). Komunikasi Kesehatan Sebuah Tinjauan. Jurnal Psikolognesis, 1(1), 88-94.

Retnaningsih, D., Kustriyani, M., \& Sanjaya, B. T. S. (2017). Perilaku Merokok dengan Kejadian Hipertensi pada Lansia. Prosiding Seminar Nasional \& International, 122-130. https://jurnal.unimus.ac.id/index.php/psn12012010/article/view/2284/2264

Roca, B., Nadal, E., Rovira, R.E., Valls, S., Lapuebla, C., \& Lloria, N. (2003). No TitleRoca, B., Nadal, E., Rovira, R.E., Valls, S., Lapuebla, C., \& Lloria, N. (2003). Usefulness of a hypertension education program, Southern Medical Journal, 96 (11). Southern Medical Journal, 96(11).

Sinuraya, R. K., Siagian, B. J., Taufik, A., Destiani, D. P., Puspitasari, I. M., Lestari, K., \& Diantini, A. (2017). Assessment of Knowledge on Hypertension among Hypertensive Patients in Bandung City: A Preliminary Study. Indonesian Journal of Clinical Pharmacy, 6(4), 290-297. https://doi.org/https://doi.org/10.15416/ijcp.2017.6.4.290

Susanti, M.T , Suryani, M, \& S. (2012). Pengaruh pendidikan kesehatan tentang hipertensi terhadap pengetahuan dan sikap mengelola hipertensi di puskesmas pandanaran semarang.

Sutanto. (2010). Blocking the modern diseases. ANDI Offset.

Tirtana, A. (2014). Pengaruh Pendidikan Kesehatan Terhadap Pengetahuan Hipertensi Pada Lansia Hipertensi Di Rw 04 Tegal Rejo Kelurahan Tegal Rejo.

Wulansari, J ., Ichsan, B. and Usdiana, D. (2013). 'Hubungan Pengetahuan Tentang Hipertensi Dengan Pengendalian Tekanan Darah Pada Pasien Hipertensi di Poliklinik Penyakit Dalam RSUD DR. MOEWARDI SURAKARTA.' Biomedika, 5(1), 17-22. 